\title{
КОММУНИКАТИВНО-ДЕЯТЕЛЬНОСТНЫЙ ПОДХОД В ОБУЧЕНИИ ИНОСТРАННОМУ ЯЗЫКУ (НА ПРИМЕРЕ ПРАКТИЧЕСКОГО КУРСА РУССКОГО ЯЗЫКА ДЛЯ УЧАЩИХСЯ ВОЕННЫХ ВУЗОВ)
}

\author{
Доц. др. Елена Казимянец, доц. др. Дилета Ятаутайте \\ Литовская военная академия им. генерала Йонаса Жямайтиса
}

\begin{abstract}
Аннотация. Статья посвящена анализу новейших методов и технологий обучения иностранным языкам, используемых военной аудитории. Особое внимание авторы уделяют рассмотрению преимуществ и недостатков метода САЦ ("Student centered learning") и возможности его сочетания с методом активизации и традиционными методами обучения. В результате анализа авторы приходят к выводу, что только гармоничное сочетание комплекса методов и приёмов может обеспечить успех всего прочесса обучения. Автор подчёркивает необходимость включения в учебный процесс дистанционных и компьютерных технологий, так как на их основе можно строить принциииально новые формы обучения, отвечающие потребностям современного общества. В статье также рассматриваются принципы построения нового учебного пособия по русскому языку для учащихся военных учебных заведений, основанного на современном понимании методов обучения иностранным языкам и учитывающем специфику военной аудитории.
\end{abstract}

Ключевье слова: технологии обучения, метод САЦ, метод активизации, аудиовизуальный метод, дистанционные технологии обучения, РКИ, традиционная модель обучения, интенсификация учебного процесса.

\section{Введение}

Изменившаяся геополитическая ситуация в Европе требует нового подхода к обучению иностранным языкам, в том числе и в военных вузах. Современный военный специалист, помимо родного и английского языков, должен уметь общаться ещё, как минимум, на одном иностранном языке, причём не только на бытовом уровне, но и в условиях профессиональной коммуникации. Практика преподавания иностранных языков в Литовской военной академии показывает, что русский язык становится приоритетным предметом из числа свободно выбираемых языковых дисциплин. Количество кадетов, ориентирующихся на изучение русского языка в качестве второго иностранного, за 
последние пять лет ежегодно растёт (с 7 кадетов в 2013 до 24 человек в 2017 году). Однако уровень знания выбранного языка учащимися значительно различается в обучаемой группе. В одной языковой группе оказываются кадеты, вообще не изучавшие русский язык ранее, и те, которые изучали данный язык как второй иностранный в школе. Кроме того, объём аудиторных (контактных) часов, выделяемых программой на изучение второго иностранного языка, ограничен, а в задачи обучения входит не только изучение общих разговорных тем, грамматического и лексического минимума, но и подготовка военного специалиста к профессиональному общению на иностранном языке, предполагающему знание военной терминологии. Такая постановка вопроса диктует необходимость интенсификации процесса обучения иностранному языку и совершенствования методов и подходов, использующих возможности современных обучающих технологий, в преподавании иностранного, в том числе русского, языка в военной аудитории. Перед преподавателем встаёт проблема тщательного отбора изучаемого материала: с одной стороны его минимизации и политической корректности, и с другой стороны, учебный материал должен удовлетворить потребности как профессионального, так и бытового общения. Всё это стимулирует методический поиск теоретической платформы нового учебника по русскому языку, отвечающего целям и задачам обучения и основанного на современных методах обучения с учётом специфики военного вуза.

Целью данной статьи является освещение и анализ современных методов и технологий обучения иностранным языкам и возможности их использования на практических занятиях по РКИ в военном вузе.

В соответствии с поставленной целью в рамках данной работы предполагается решить следующие задачи:

- охарактеризовать сущность, преимущества и недостатки коммуникативно-деятельностного подхода в обучении иностранным языкам, а также возможность его применения в сочетании с другими методами обучения;

- показать возможности его использования на практических занятиях по РКИ в военном учебном заведении;

- проанализировать целесообразность использования элементов дистанционного обучения в рамках коммуникативно-деятельностного подхода при изучении русского языка в литовской военной академии;

- познакомить с опытом создания учебного пособия нового типа по русскому языку для учащихся военных вузов, основанном на коммуникативно-деятельностном подходе к обучению и рассчитанном как на контактное, так и на дистанционное обучение.

В статье использованы описательный и аналитический методы исследования. 


\section{Основная часть}

Современный процесс изучения иностранных языков характеризуется интенсивным использованием самых разнообразных методик и методов обучения, предполагающих:

- максимальную интенсификацию использования аудиторного учебного времени за счёт привлечения новейших учебных технологий;

- активное привлечение учебных и аутентичных аудиовизуальных материалов в процессе обучения;

- ориентацию на возможность использования компьютерных технологий в обучении языку, особенно при самостоятельной работе учащихся и при дистанционном обучении;

- индивидуальный подход к обучению - предложенные кадетам для изучения тексты и задания должны в идеале быть дифференцированы в соответствии с уровнем знаний каждого кадета.

В рамках данной статьи невозможно проанализировать все рекомендуемые методической наукой современные техники обучения. Остановимся на важнейших, с нашей точки зрения, и наиболее перспективных методах обучения в условиях преподавания второго иностранного языка в Литовской военной академии. Специфика преподавания иностранного языка в военной аудитории обусловлена требованиями, предъявляемыми к языковой компетенции выпускника военного вуза. Выпускник военной академии, должен обладать следующими качествами, требующими соответствующей языковой подготовки:

- быстро ориентироваться в меняющихся жизненных ситуациях, активно приобретая необходимые языковые знания и умело применяя их на практике;

- самостоятельно критически и творчески мыслить, быть способным осознать, где и каким образом приобретаемые языковые знания могут быть использованы;

- грамотно работать с информацией на иностранном языке;

- быть при необходимости коммуникабельным в самых разных ситуациях общения с представителями различных социальных и национальных групп;

- уметь работать в интернациональной команде, предотвращать конфликтные ситуации и выходить из них;

- стремиться к повышению собственного культурного и языкового уровня (Казимянец, 2016: 207; Краснова, 2009: 4-5).

Одним из продуктивных и широко используемых направлений в обучении иностранному языку представляется эмпирический подход, реализованный в так называемом методе САЦ - «студент как активный центр учебного процесса», позволяющий по-новому взглянуть на роль преподавателя и 
студента в учебном процессе и дать возможность обучаемому проявить свой потенциал, самостоятельность и независимость от преподавателя. На основе этого метода строится модель обучения иностранному, в частности русскому языку, где кадет становится активным центром учебного процесса. Принимая во внимание изложенные выше требования к языковой подготовке военного специалиста, считаем, что именно данный метод наиболее уместен в преподавании русского языка в условиях обучения кадетов.

Как известно, традиционный подход к изучению иностранного языка базируется на принципе ведущей роли преподавателя не только в аудитории при непосредственном контакте с учащимися, но и в вопросе определения объёма и содержания учебного материала и методов его подачи на занятиях. В данной модели обучения студентам отводится сравнительно пассивная роль. Методы, основанные на традиционной модели, вполне допустимы и дают хорошие результаты в аудитории, где уровень знаний учащихся примерно одинаков. Но следует заметить, что данный подход к изучению языка в группах с разным уровнем владения иностранным языком учащихся увеличивает «пропасть» между сильными и слабыми студентами, вызывая «комплекс безнадёжности» у последних. Боязнь показаться смешным или несведущим изолирует обучаемых друг от друга, лишая их возможности проявить себя и показать свои знания. В результате мотивация к изучению языка снижается как у сильной, так и у слабой части группы. Естественно, такое положение дел стимулирует методистов на поиск новых методик обучения.

Идея равноправного сотрудничества преподавателя и студенческой группы не так уж нова и впервые возникла в области методической науки преподавания иностранных языков в 80-х годах прошлого столетия. Учёные (R. J. Stevens, N. A. Madden, R. E. Slavin и др.) провели экспериментальные исследования и доказали значительно большую эффективность кооперативного подхода (метода кооперации) в обучении иностранным языкам по сравнению с традиционным методом. В 90-х годах данная идея обогащается и развивается в работах, освещающих разработку процессуально-ориентированной модели овладения иностранным языком. Суть этой модели состоит в том, что преподаватель ставит перед студентами «интерактивную задачу», которая решается студентами сообща с использованием уже имеющегося у них языкового опыта (J. Bruner, 1983). Вышеназванные исследования послужили фундаментом для разработки так называемого метода "learner centered instruction", при котором учащиеся являются активным центром учебного процесса. В дальнейшем этот подход получил название эмпирического изучения языка [Казимянец, 2002, с. 60]. По утверждению Д. Колба (D. Kolb, 1984, с. 21- 42), при эмпирическом подходе к обучению определяющую роль играет непосредственный опыт обучаемого: абстрактные понятия, вводимые в процессе обучения, преломляются через языковой опыт обучаемого, приобретая, таким образом, объёмное восприятие и субъективное понимание. С другой стороны, сам непо- 
средственный опыт, в свою очередь, в ходе постижения абстрактных понятий также подвергается анализу, что даёт возможность описать процесс изучения иностранного языка в виде цикла, включающего в себя непосредственный, конкретный опыт, подвергающийся анализу, который ведёт к абстрактной концептуализации, реализующейся в конкретных действиях, то есть в определённом языковом поведении. Для наглядности, базируясь на теории Д. Колба, представим данный цикл в виде схемы:

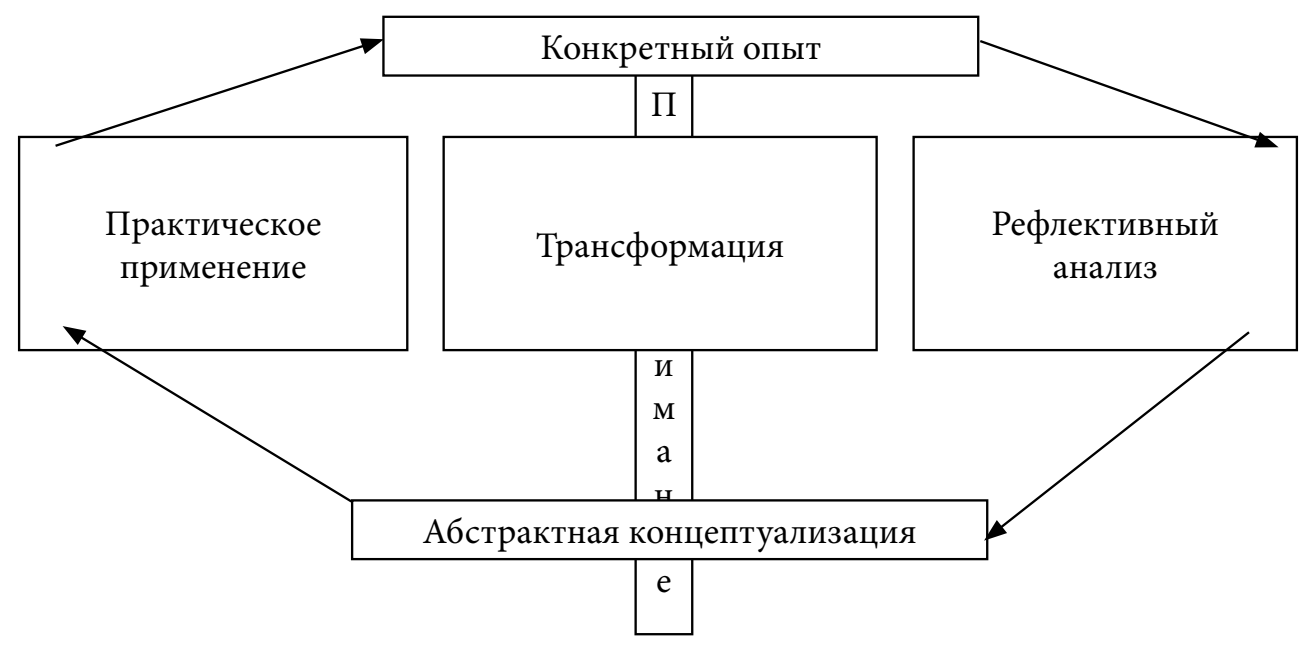

Схема Д. Колба (Kolb, 1984, с. 42)

В описываемой модели изучение нового материала представляет собой процесс понимания нового и его дальнейшей трансформации в речевых структурах и в процессе общения, где под пониманием подразумевается то, каким образом обучаемый приобретает опыт, а под трансформацией - как учащийся использует полученные знания. Можно выделить два типа трансформации:

- активный эксперимент - активную речевую деятельность, в ходе которой учащиеся свободно используют полученные знания, не боясь возможных ошибок и совершая их;

- вдумчивое, постепенное размышление и усвоение нового материала, при котором обучаемые предпочитают более медленный путь достижения результата во избежание возможных ошибок.

Как видно из представленной выше схемы, понимание нового и его трансформация проходят четыре стадии в циклическом процессе эмпирического изучения иностранного языка:

- приобретение конкретного языкового опыта (с привлечением индивидуального опыта и превалирования чувственного восприятия над процессом мышления); 
- процесс абстрактной концептуализации на основе использования логического мышления и системного подхода к решению проблем;

- рефлективный анализ, направленный на понимание новых идей, материала, ситуаций на основе собственных знаний, суждений, представлений и чувств;

- практическое применение приобретённых знаний в конкретных речевых ситуациях.

Данные теоретические положения легли в основу сравнительно нового подхода к преподаванию иностранных языков, в том числе русского, который получил название "Student centered learning” (САЦ), где на первый план выдвигается студент как активный центр учебного процесса. Модель САЦ позволяет создать атмосферу партнёрства, общей цели и совместного управления процессом обучения. Успешная работа в аудитории обеспечивается активным участием каждого студента группы, причём преподаватель также является равноправным её членом. Заметим, что при использовании традиционной модели обучения студенты, как правило, работают индивидуально, и кооперация между ними фактически сводится к соревнованию за оценки (Казимянец, 2002, с. 60-61).

Эмпирическая модель (САЦ), безусловно, имеет ряд преимуществ по сравнению с традиционной моделью. Как показывает опыт преподавания русского языка в ЛКА, традиционная модель обучения не гарантирует усвоение нового материала всеми кадетами группы, что объясняется пассивной ролью учащегося, и, кроме того, далеко не каждый кадет способен применить полученные теоретические знания на практике, то есть при продуцировании речи в условиях учебного и реального общения. В то время как новый подход, во-первых, не оставляет ни одного кадета группы пассивным и даёт возможность каждому студенту самостоятельно вывести необходимые алгоритмы продуцирования правильной речи на изучаемом языке на основе собственного эмпирического опыта. Во-вторых, данный подход значительно повышает мотивацию кадетов в изучении иностранного языка, так как предоставляет им свободу в выборе средств и путей решения поставленной преподавателем задачи. В-третьих, следует принять во внимание, что повышение мотивации и осознание собственной активной роли в процессе постижения языка стимулируют учащегося на преодоление возможных трудностей и ведут к успеху в изучении иностранного языка в целом, ибо успех в изучении иностранного языка напрямую связан с уверенностью кадета в своих силах. Кроме того, равноправное и творческое участие кадетов в учебном процессе как нельзя лучше удовлетворяет требованию воспитания у них способности самостоятельно пронимать решения, оценивать ситуацию, ставить задачу и развивает лидерские качества, столь необходимые будущему офицеру. И, наконец, в-четвёртых, творческое равноправие и сотрудничество преподавателя 
и обучаемого, с одной стороны, избавляет учащегося от боязни совершения ошибок, а с другой - снимает с преподавателя роль постоянного арбитра, что способствует созданию атмосферы реального, непринуждённого общения на иностранном языке.

Несмотря на очевидные положительные факторы использования метода САЦ, нельзя не отметить и ряд недостатков, присущих данной модели. Заметим, что традиционная модель обучения, широко используемая в средней школе до сих пор и основанная на авторитарном лидерстве учителя, заранее «настраивает» кадетов на пассивную роль в учебном процессе при изучении второго иностранного языка. Поэтому складывается объективная трудность вовлечения кадетов в работу в аудитории на основе равноправного сотрудничества с преподавателем, и это вынуждает последнего зачастую возвращаться к роли ведущего в учебном процессе. Более того, замечено, что ориентация кадета на хорошую отметку мешает ему объективно оценить свои знания. Многие кадеты вообще предпочитают полагаться на оценку преподавателя, будучи не в состоянии оценить себя сами. Таким образом, учащимся оказывается трудно преодолеть сложившийся в системе средней школы стереотип «ведомого» и адаптироваться к новой для него роли партнёра, предлагаемой при обучении по модели САЦ. Надо также принять во внимание, что существующие учебники, например, по русскому языку как иностранному, ориентированы в большей степени на традиционную модель обучения и мало подходят для работы по модели САЦ.

Практика преподавания иностранных языков, в частности русского, в Литовской военной академии и со слушателями (работниками различных силовых структур) языковых курсов показывает невозможность следования только одной модели обучения. Изменившиеся условия обучения (например, возможность дистанционного обучения и использования компьютерных технологий, доступность аудиовизуальных средств обучения в аудитории) и стремительное развитие обучающих технологий в целом создают благодатную почву для ввода в учебный процесс модели, представляющей собой некий комплекс методических методов и приёмов, использующих наряду с традиционными методами обучения и новейшие методические технологии. Остановимся на некоторых из них.

Одним из наиболее эффективных методов обучения иностранному языку и гармонирующих с вышеописанным методом САЦ можно назвать метод активизации. Данный метод применяется чаще всего в условиях отсутствия реальной языковой среды и как нельзя лучше способствует усвоению большого количества новой лексики в единицу учебного времени. В сочетании с методом САЦ, метод активизации несомненно помогает создать необходимые условия для успешного партнёрства преподавателя и кадетов, интенсификации и оживления процесса обучения, повышения мотивации к изучению языка и, в конечном счёте, способствует достижению прекрасных результатов в 
овладении иностранным языком как средством общения. Метод активизации (MA) можно охарактеризовать как научно обоснованную концепцию обучения, целью которой является «обучение общению на иностранном языке через общение». Данная концепция, в свою очередь, предполагает ряд вполне определённых особенностей организации учебного процесса, базирующихся на конкретных психолого-педагогических принципах (Титкова, 2013: 33). Основные принципы, служащие теоретическим фундаментом данного метода, сводятся к следующему:

Во-первых, принцип личностно-ориентированного общения, который подразумевает максимальное слияние общения и обучения и составляет кредо МА - обучающее общение. Сейчас ни у кого не вызывает сомнения, что личностное общение помогает установить в группе доверительные отношения, снимает скованность у обучаемых и способствует наиболее продуктивному овладению иностранным языком. Но для преподавателя РКИ, работающего по методу активизации, - это инструмент планирования и построения занятия, способ общения с кадетами, который закладывается в сценарий каждого занятия. Методически грамотное общение требует от преподавателя определённого стиля работы, который предполагает:

- отбор или создание текстов, отвечающим личностным и профессиональ ным интересам кадетов, а также умение привязывать их к конкретной теме, представленной в учебнике;

- создание и формулировка заданий, предполагающих множественность ответов и, таким образом, стимулирующим общение (это варианты заданий, связанные с дискуссиями, обсуждениями, полемикой, т. е. задания, где кадету необходимо изложить свою точку зрения на проблему или по поводу прочитанного или услышанного);

- не оценивание ответа кадета, а корректировка с учётом грамматической и лексической правильности и с акцентом на выражение отношения к содержанию его высказывания;

- отказ от фронтального опроса и умение передавать реплику (ответ, высказывание) одного кадета другим, там самым провоцируя их на собственные высказывания и реакции, что, в конечном счёте, стимулирует активность диалога в группе;

- умение «вплетать» в контекст вроде бы неформального личностного общения учебный материал (в частности - упражнения) и, наоборот, привнесение в сугубо учебный материал личностного содержания (Казимянец, 2016: 212-213)

Таким образом, преподаватель, действительно, выступает в качестве «дирижёра», организатора и равноправного участника учебного процесса, его ведущая роль, если так можно выразиться, сводится именно к созданию необходимых предпосылок для всего процесса обучения в рамках поставленных 
программой задач и определённых тем.

Во-вторых, принцип ролевой организации учебного материала и процесса обучения. В данном случае хочется подчеркнуть, что ролевое общение это не фрагмент занятия по РКИ, если речь идёт об интенсификации обучения. Специфика ролевого учебного общения состоит в том, что оно сохраняет все социально-психологические характеристики истинного, реального общения, которое само по себе всегда мотивировано, имеет вполне конкретные цели и предполагает наличие активных субъектов общения - реальных людей с их интересами, вкусами, настроением. При построенном на принципе интенсификации занятии преподаватель:

- постоянно создаёт мотивы для речевого действия участников процесса коммуникации, однако само общение осуществляется кадетами, что вполне созвучно целям и установкам метода САЦ;

- даёт кадетам возможность проигрывать различные модели социального поведения, которые выбираются самими кадетами, и это также осуществляется в рамках метода САЦ;

- помогает им преодолевать языковой барьер, снимает чувство неловкости из-за допущенных языковых ошибок и в то же время предоставляет им возможность пробовать себя в новых ролях, примерять на себя новые качества и обстоятельства, полагаясь на самостоятельный выбор обучаемого, а данный подход также укладывается в рамки метода САЦ.

В-третьих, в рамках МА задействован принцип концентрированности в организации учебного материала и учебного процесса, который связан, прежде всего, с объёмом изучаемого материала и его распределением в курсе русского языка. Данный принцип предполагает взаимодействие и взаимозависимость достаточно большого объёма изучаемого материала и способствует активизации учебно-познавательной деятельности. Такая взаимозависимость носит двусторонний характер: активизация учебной деятельности и повышение темпа занятия, с одной стороны, создаёт почву для успешного усвоения повышенных объёмов концентрированной учебной информации, а с другой стороны, насыщенность новой информацией учебного материала активизирует познавательную деятельность и способность кадетов к усвоению нового. Как утверждает С. Титкова, учащийся перестраивается на более активный режим работы, который способствует максимальным проявлениям его творческих способностей, в частности способности запоминать большие объёмы информации без предварительного заучивания. Надо отметить, что в данном случае очень важно правильно распределить учебный материал, предназначенный для аудиторной и самостоятельной работы кадетов. Наш опыт показывает, что домашние задания должны состоять из заданий, на 80\% включающих уже известный кадетам материал и выполнять функцию повторения и обобщения пройденного, закрепления новой изученной на занятии лексики 
и грамматики. Также обязательны творческие домашние задания, направленные на поиск в интернете информации, связанной с их будущей профессиональной деятельностью (Казимянец, 2016: 213-214). Такой подход позволяет учащимся проявить самостоятельность, творческую инициативу, проявить и реализовать свои способности, интересы и вкусы.

Существует ряд способов активизации познавательной деятельности учащихся. В качестве примера можно упомянуть такой методический приём как опережающее программу введение сложных речевых конструкций, например, - сравнительных оборотов с союзом чем или вроде без их грамматического анализа для того, чтобы дать возможность кадетам пользоваться речевыми моделями на раннем этапе обучения. Другой способ активизации познавательной деятельности, укладывающийся в схему обучения по методу САЦ, связан с предваряющим характером домашнего задания, когда кадет сначала знакомится с новым материалом (чаще грамматическим) самостоятельно, и только потом на занятии его (в случае необходимости) объясняет преподаватель или кадет, сумевший разобраться в данном вопросе самостоятельно. В таком случае при необходимости преподавателю отводится роль «корректировщика» пояснения кадета. Добавим, что в учебнике есть грамматический комментарий, с которым кадеты вполне способны разобраться сами. Другими словами, выстраивается следующая «цепочка» подачи материала: самостоятельный анализ теории (грамматического материала) кадетом --- выполнение домашнего задания --- объяснение преподавателя или товарища в случае необходимости. Кроме того, оказывается весьма продуктивной самостоятельная домашняя работа кадетов с видеоматериалом, на основе которого предлагается выполнить ряд заданий дома и позже в аудитории. Например, даже на раннем этапе обучения можно предложить учащимся дома на основе просмотра предложенных преподавателем видеосюжетов, которые преподаватель может поместить в Инете, вывести речевые формулы, характерные для официального и неофициального знакомства, а также речевого этикета представления военных. В качестве материала можно предложить самые разные эпизоды из мультфильмов, художественных кинолент. Мы придерживаемся точки зрения, что такая организация учебного процесса стимулирует активное, осознанное участие кадета в занятии независимо от того, смог ли он самостоятельно разобраться с новым языковым материалом, либо понял недостаточно хорошо или не понял вовсе.

Аудиовизуальный метод также прекрасно сочетается с вышеописанными методами обучения иностранным языкам. Он особенно продуктивен в условиях отсутствия реальной речевой среды, так как с видеосюжетом в учебную аудиторию приходит сама жизнь. Учащиеся видят естественный процесс общения во всём его объёме (включая мимику, жесты, интонацию, внелингвистические факторы конкретного момента общения), погружаясь в мир носителей языка. Иными словами иллюстративно-графическое представ- 
ление фрагментов знаний - фактически жизненных ситуаций, осуществляемое с помощью аудиовизуальных средств - то есть с использованием звука, движения, цвета, позволяет задействовать резервы интеллектуальной сферы кадетов, развить их образную память, увидеть информацию в полном объёме и затем учиться анализировать её по представленным образцам элементов. Кроме того, удачно подобранная и методически разработанная преподавателем видеовставка оживляет и разнообразит занятие, стимулирует кадетов к активному участию в работе над сюжетом, повышает мотивацию к изучению языка. Использование видеосюжетов существенно экономит учебное время, так как большая часть лексического материала становится ясной из увиденного на экране и хорошо усваивается кадетами без дополнительных комментариев преподавателя.

Хотелось бы также остановиться на информационно-коммуникативных технологиях (ИКТ), которые всё больше применяются в преподавании РКИ. Это и электронные учебники, и интерактивные обучающие пособия (тренажеры), и виртуальные среды, компьютерные презентации, инструменты для создания учебных материалов, справочно-информационные источники (он-лайн-переводчики и словари) и многое другое. В учебный процесс активно вовлекаются дистанционные технологии, которые, безусловно, делают весь процесс обучения современным, интенсивным и - что не менее важно -, интересным для обучающихся. Более того, нельзя не отметить ряд исключительно привлекательных и положительных моментов, связанных с использованием дистанционных технологий в преподавании иностранного языка. Это, во-первых, доступность обучения независимо от места нахождения обучаемого: любой учащийся может получить необходимый ему пакет образовательных услуг в индивидуальном режиме. Во-вторых, при дистанционном обучении задействованы новые формы и разные типы представления информации: от графических текстов, картинок, таблиц до видео и анимации, которые сопровождаются огромным объёмом справочной, основной и дополнительной информации. В-третьих, вводятся новые формы проверки и сертификации знаний и умений на основе использования тестов, рефератов, проектов и др. (Азимов, 2011: 47). В принципе дистанционные технологии предполагают наличие следующих составляющих: чётко разработанных учебных ресурсов методических и справочных материалов, учебных пособий и специальных курсов, преподавателя-консультанта и самих обучающихся. Благодаря применению дистанционных технологий осуществляется индивидуальный подход к обучению, обеспечивается диалоговый характер взаимодействия преподавателя и учащегося, а сочетание онлайнового способа взаимодействия преподавателя и слушающего и офлайнового (когда обучающийся использует информационные ресурсы постоянно находящиеся в Интернете) позволяет наиболее эффективно использовать учебное время. Непременным условием рационального использования данного метода является системное проведение текущего 
и итогового контроля, регулярное обновление учебных материалов, сочетание дистанционных и традиционных форм обучения и др. Рассматривая возможности использования дистанционных средств обучения в схеме общей платформы метода САЦ, отметим, что такой подход, с одной стороны, объединяет усилия преподавателя и учащихся и обеспечивает успешное усвоение содержания курса, а с другой, позволяет интегрировать в учебный процесс новые виды взаимодействия между преподавателем и кадетами, организуя самостоятельную работу кадетов и обеспечивая преобладание самоконтроля над контролем со стороны преподавателя.

В настоящее время создано немало различных дистанционных курсов русского языка как иностранного в Интернете, однако ни один из них с точки зрения профессиональной направленности и содержания обучения не удовлетворяет потребностям военной аудитории. Таким образом, для успешного обучения иностранному языку в Литовской военной академии назрела необходимость создания нового учебного пособия по русскому языку, ориентированного на военную аудиторию, теоретической базой которого являлось бы органичное и продуманное сочетание традиционных методов преподавания иностранных языков с новейшими методами и технологиями обучения. Иными словами, появилась потребность в учебном пособии, которое могло бы быть успешно использовано не только при аудиторной работе, но и в условиях, когда преподаватель и кадет в силу разных обстоятельств разделены расстоянием, то есть пригодное для дистанционного обучения. Работа над созданием такого пособия уже ведётся. Отличительными чертами данной учебной книги, помимо использования комплекса вышеописанных методов обучения, представляется целый набор характеристик, учитывающий не только специфику военного вуза, возможность дистанционного обучения, но и разный уровень владения языком кадетами, а именно:

Параллельное введение разговорных тем общего характера с речевыми ситуациями профессионального общения.

- Содержание учебных материалов предполагает возможность индивидуальной работы с кадетами, имеющими неодинаковый уровень знания русского языка, то есть в пособие вводятся тексты, диалоги, упражнения разной степени трудности на одну и ту же тему.

- Обеспечение усвоения словарного минимума, необходимого для повседневного и профессионального общения, включая военную терминологию, на основе текстов и специально разработанных заданий и упражнений.

- Минимизация грамматического блока учебной книги, который в основном представлен в грамматических таблицах и обеспечивает необходимые и достаточные знания грамматики для продуцирования правильной русской речи в условиях реального общения на русском языке.

- Обеспечение потребностей аудиторного, самостоятельного и дистанционного обучения. 
- Погружение кадетов в реальную русскую речевую среду за счёт введения аудиовизуальный блока, стимулирующего развитие речевых навыков, повышение мотивации к общению на русском языке в учебных условиях.

- Использование для обучения возможностей Youtube, с помощью которого размещается подобранная учебная информация, просматриваются видео файлы в Интернете.

\section{Выводы}

Таким образом, можно сделать вывод, что в настоящее время успешное овладение вторым иностранным языком во многом зависит от оптимального сочетания методов и приёмов обучения. Практика преподавания РКИ в Литовской военной академии показывает целесообразность организации учебного процесса на базе эмпирического подхода, где ведущим методом обучения признаётся метод САЦ (студент - активный центр) в сочетании с методом активизации, аудиовизуальным и традиционными методами обучения. Такая модель обучения как нельзя лучше способствует выработке у кадетов не только прочных языковых навыков и умений, но и развивает лидерские качества будущего офицера, способность к принятию самостоятельных решений и его творческий потенциал. При использовании такого подхода к обучению меняется традиционная роль преподавателя в качестве ведущего, лидирующего в учебном процессе, и взаимоотношения преподавателя и кадетов переходят в плоскость тесного сотрудничества и равноправного партнёрства. Всё это улучшает качество обучения, повышает мотивацию кадетов к изучению иностранного языка, настраивает их на преодоление возможных трудностей и снимает боязнь возможных ошибок при общении на иностранном языке. Кроме того, данный комплекс методов прекрасно «работает» в аудитории, где уровень знаний языка учащихся неодинаков. Не менее важно включать в учебный процесс и дистанционные технологии, так как на их основе можно строить принципиально новые формы обучения, позволяющие преподавателю создавать и размещать в Интернете учебные материалы, тренировочные упражнения и тестовые задания, методически разработанные видеоматериалы и др. Заметим, что дистанционные технологии особенно полезны в условиях, когда непосредственный контакт с преподавателем невозможен. Несмотря на то, что в настоящее время существует немалое количество различных дистанционных курсов русского языка, далеко не все они соответствуют и отвечают потребностям изучения русского языка в военной аудитории, где на первый план выдвигается необходимость изучения профессиональной лексики и военной терминологии, которое должно осуществляться параллельно с вводом общеупотребительной лексики на всех этапах обучения. Более того, в условиях ограниченного учебного времени первостепенную важность приобретает также и интенсификация учебного процесса. Заметим, что доступность 
новых технических средств обучения предполагает не только интенсификацию процесса обучения и модификацию методических средств, но и перераспределение и новую организацию содержания обучения, что должно найти отражение в современных учебных пособиях по иностранному, в частности русскому, языку. Таким образом, думается, что назрела необходимость в создании специализированного пособия по русскому языку, учитывающему цели и специфику обучения иностранному языку в военных вузах и основанного на современных методических технологиях с учётом возможностей как аудиторного, так и дистанционного обучения.

\section{Литература}

1. Азимов, Эльхан Г. (2011). Информационно-коммуникационные технологии в обучении РКИ: состояние и перспективы. Русский язык за рубежом, N 6. C. 45-55.

2. Казимянец, Елена (2016). Современные методические технологии на практических занятиях по русскому языку в Литовской военной академии. Šiuolaikinès visuomenès ugdymo veiksniai. Mokslo žurnalas. - 1 tomas. - Vilnius: LKA, p. 205-218.

3. Казимянец, Елена (2002). Коммуникативно-деятельностный подход в обучении русскому языку студентов-иностранцев. Žmogus ir žodis. Mokslo žurnalas.- N. 3. Vilnius: LEU, p. $59-63$.

4. Краснова, Светлана В. (2009) Дружно за мир стоять - войне не бывать. Обучение курсантов-инофонов военной лексике на подготовительном отделении. Русский язык за рубежом, N3.C.4 - 22.

5. Титкова, Светлана И. (2013). Специфика реализации принципов метода активизации в программе обучения русскому языку студентов Летней школы Миддлбери. Русский язык за рубежом, N1. С. 33 - 42.

6. Bruner, J. (1983). In Search of Mind: Essays in Autobiography. - New York: Harper and Row.

7. Kolb, A. (1984). Experience Learning as the Source of Learning and Development. Englewood Cliffs, N. J.: Prentice Hall.

8. Nunan, D. (1992). Collaborative Language Learning and Teaching. Cambridge: Cambridge University Press.

9. Slavin, R. E. (1983). Cooperative Learning. New York: Logman.

10. Stevens, R. J., Madden, R. E., Slavin, R. E., and Farnish, A. M. (1987). Cooperative Integrated Reading and Composition: Two Field Experiments. Reading Research Quarterly. 22 (4). 


\title{
COMMUNICATIVE ACTIVITY APPROACH IN TEACHING A FOREIGN LANGUAGE (ON THE BASIS OF THE PRACTICAL COURSE OF RUSSIAN FOR THE STUDENTS OF MILITARY UNIVERSITIES)
}

\author{
Assoc. Prof. Dr. Jelena Kazimianec \\ The General Jonas Žemaitis Military Academy of Lithuania \\ Assoc. Prof. Dr. Dileta Jatautaitė \\ The General Jonas Žemaitis Military Academy of Lithuania
}

\section{Summary}

The object of the article is to highlight and analyze the latest methods and technologies of teaching foreign languages and reveal a possibility of using them in practical course of the Russian language for foreigners at military universities and schools. The article gives a brief overview of traditional and empirical approaches to teaching foreign languages and reveals the advantages and disadvantages of the methods used by methodologists.

Particular attention is paid to the analysis of the SCL (student-centered learning) method as the most promising method for teaching a foreign language at a military college despite some of its shortcomings and difficulties associated with its implementation. The authors have become firmly convinced that when taking into account the tasks facing a foreign language teacher with the military audience, it is reasonable to accomplish training on the basis of an active and equal partnership of a teacher and cadets, which can be achieved when using the SCL method.

The activation method (AM) is recognized as one of the most effective methods of teaching a foreign language when it is used in combination with the SCL method. The authors suppose that the AM can be described as a scientificallybased concept of learning, the purpose of which is learning to communicate in a foreign language through communication. This method is used most often in the absence of a real language environment and is the best way to assimilate a large number of new words in a unit of study time. In combination with the SCL method and traditional teaching methods, the AM undoubtedly helps to create necessary conditions for a successful partnership of a teacher and cadets.

The authors have come to the conclusion that only a harmonious combination of a set of methods and techniques can ensure the success of learning process. In addition, changed learning conditions (for example, distance learning possibility, use of computer technologies and availability of audiovisual teaching means in the 
classroom) and rapid development of teaching technologies in general create fertile ground for introducing into the educational process a model that contains a set of methodical techniques which are based on the combination of traditional methods of teaching and the latest methodological technologies.

The article also deals with the principles of constructing a new textbook on the Russian language for students of military educational institutions which is based on a modern understanding of the methods of foreign language teaching and takes into account the specifics of military audience. The authors emphasize a need to include modern distance technologies into the educational process, since it is possible to build fundamentally new forms of education on their basis.

Keywords: teaching technologies, SCL method, activation method, audiovisual method, distance learning technologies, Russian as a foreign language, traditional model of training, intensification of the learning process 


\section{AUTORIŲ LYDRAŠTIS}

Autoriaus vardas, pavardė: Jelena Kazimianec

Mokslo laipsnis ir vardas: humanitarinių mokslų daktarè, docentė

Darbo vieta ir pareigos: Generolo Jono Žemaičio Lietuvos karo akademijos Universitetinių studijų instituto Užsienio kalbų katedros docentė

Autoriaus mokslinių interesų sritys: dabartinė rusų kalba, rusų kalbos gramatika, lingvokultūrologija, svetimujų kalbų dėstymo didaktika, sociolingvistika, komparatyvistinè lingvistika

Telefonas ir el.pašto adresas: + 37068759 272; jelena.kazimianec@1ka.lt

Autoriaus vardas, pavardè: Dileta Jatautaitè

Mokslo laipsnis ir vardas: socialinių mokslų daktarè, docentė

Darbo vieta ir pareigos: Generolo Jono Žemaičio Lietuvos karo akademijos Universitetinių studijų instituto Užsienio kalbų katedros vedejja docentė

Autoriaus mokslinių interesų sritys: psicholingvistika, glotoedukologija, edukologija, tradiciniai ir netradiciniai kalbų mokymo metodai bei metodologija, psichoedukologiniai kalbų mokymo bei išmokimo pagrindai

Telefonas ir el. pašto adresas: (8 5) 210 3560; dileta.jatautaite@mil.lt

\section{AUTHORS' COVER LETTERS}

Author's name and surname: Jelena Kazimianec

Academic degree and name: Associate Professor, Doctor

Workplace and position: The General Jonas Žemaitis Military Academy of Lithuania, Institute of University Studies, Department of Foreign Languages, Associated Professor, Doctor

Author's research interests: modern Russian, Russian grammar, comparative linguistics, foreign language teaching methods, social linguistics, lingua-culturology

Telephone and e-mail address: +370 68759 272; jelena.kazimianec@lka.lt

Author's name and surname: Dileta Jatautaitè

Academic degree and name: Associate Professor, Doctor

Workplace and position: The General Jonas Žemaitis Military Academy of Lithuania, Institute of University Studies, Department of Foreign Languages, Head Author's research interests: psycholinguistics, glotoeducology, traditional and non-traditional language teaching methods and methodology, psychoeducational basis in language learning and acquisition

Telephone and e-mail address: +370 5210 3560; dileta.jatautaite@mil.lt 